\title{
Three-Dimensional Modeling and Development of the New Geometry PEM Fuel Cell
}

\section{Iman Khazaee \& Mohsen Ghazikhani}

Arabian Journal for Science and Engineering

ISSN 1319-8025

Volume 38

Number 6

Arab J Sci Eng (2013) 38:1551-1564

DOI 10.1007/s13369-013-0604-3

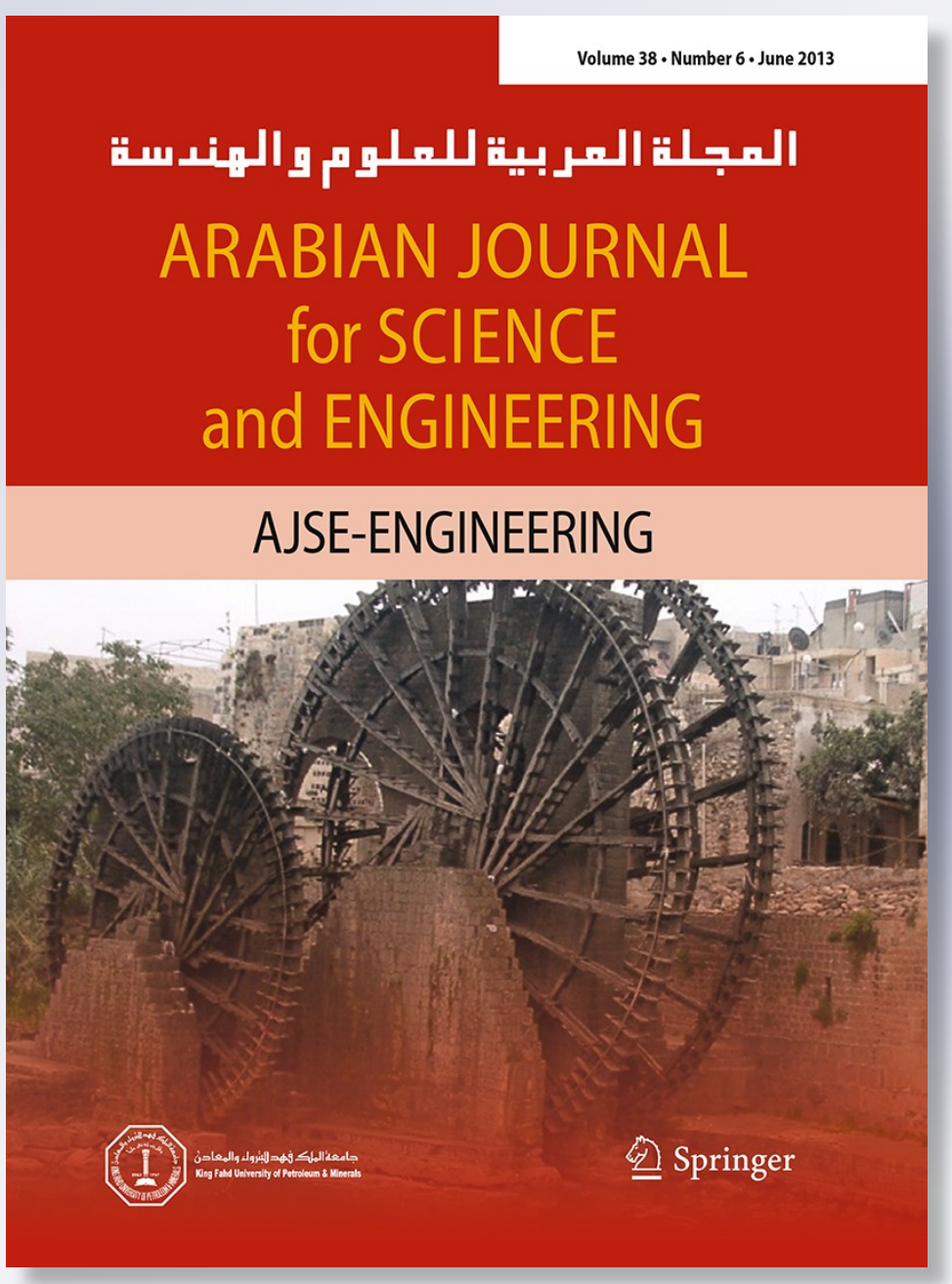

望 Springer 
Your article is protected by copyright and all rights are held exclusively by King Fahd University of Petroleum and Minerals. This eoffprint is for personal use only and shall not be self-archived in electronic repositories. If you wish to self-archive your article, please use the accepted manuscript version for posting on your own website. You may further deposit the accepted manuscript version in any repository, provided it is only made publicly available 12 months after official publication or later and provided acknowledgement is given to the original source of publication and a link is inserted to the published article on Springer's website. The link must be accompanied by the following text: "The final publication is available at link.springer.com". 


\title{
Three-Dimensional Modeling and Development of the New Geometry PEM Fuel Cell
}

\author{
Iman Khazaee • Mohsen Ghazikhani
}

Received: 9 March 2011 / Accepted: 3 May 2011 / Published online: 28 March 2013

(C) King Fahd University of Petroleum and Minerals 2013

\begin{abstract}
A complete three-dimensional and single phase computational fluid dynamics model for duct-shaped geometry proton exchange membrane (PEM) fuel cell was used to investigate the effect of using different connections between bipolar plate and gas diffusion layer on the performances, current density and gas concentration. The proposed model is a full cell model, which includes all the parts of the PEM fuel cell, flow channels, gas diffusion electrodes, catalyst layers and the membrane. Coupled transport and electrochemical kinetics equations are solved in a single domain; therefore, no interfacial boundary condition is required at the internal boundaries between cell components. This computational fluid dynamics code is used as the direct problem solver, which is used to simulate the two-dimensional mass, momentum and species transport phenomena as well as the electron- and proton-transfer process taking place in a PEMFC that cannot be investigated experimentally. The results show that the predicted polarization curves using this model are in good agreement with the experimental results. Also the results show that by increasing the number of connection between GDL and bipolar plate the performance of the fuel cell enhances and the current density at the cathode catalyst layer increases.
\end{abstract}

I. Khazaee $(\bowtie)$

Department of Mechanical Engineering, Torbat-e-jam branch, Islamic Azad University, Torbat-e-jam, Iran

e-mail: imankhazaee@yahoo.com

I. Khazaee $\cdot$ M. Ghazikhani

Mechanical Engineering Department, Engineering Faculty,

Ferdowsi University of Mashhad, Mashhad, Iran

e-mail: M_Ghazikhani@yahoo.com
Keywords PEM fuel cell · Duct-shaped · Numerical modeling · Current density · Gas concentration · Polarization

الخلاصـة

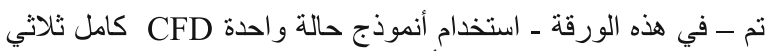

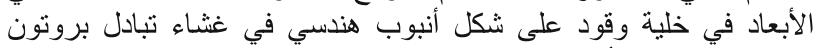

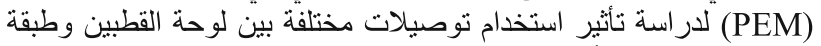

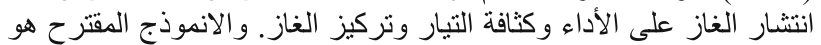

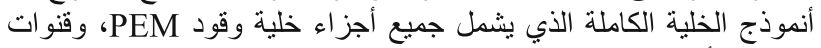

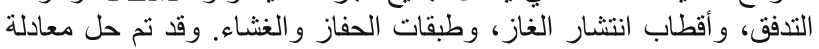

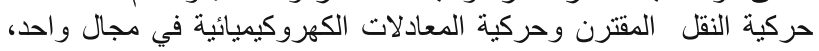

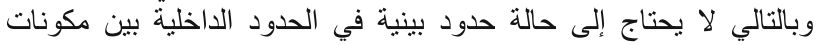

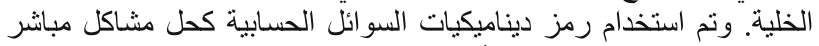

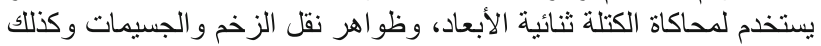

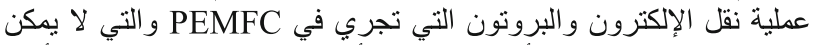

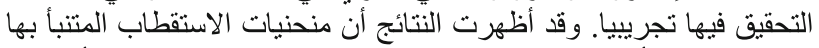

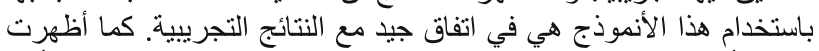

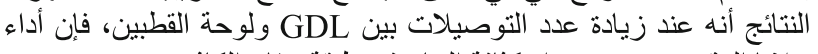
خلايا الوقود يتعزز ونزداد كثافة التيار في طبقة حفاز الكاثود.

\section{List of Symbols}

A Superficial electrode area $\left(\mathrm{m}^{2}\right)$

C Molar concentration $\left(\mathrm{mol} / \mathrm{m}^{3}\right)$

$D$ Species diffusivity $\left(\mathrm{m}^{2} / \mathrm{s}\right)$

$i \quad$ Current density $\left(\mathrm{A} / \mathrm{cm}^{2}\right)$

$i_{0} \quad$ Reference current density $\left(\mathrm{A} / \mathrm{cm}^{2}\right)$

I Current (A)

$U$ Inlet velocity $(\mathrm{m} / \mathrm{s})$

$j \quad$ Transfer current density $\left(\mathrm{A} / \mathrm{cm}^{3}\right)$

$\vec{u} \quad$ Velocity vector $(\mathrm{m} / \mathrm{s})$

$p$ Pressure $(\mathrm{Pa})$

$S$ Stoichiometric ratio

$T$ Temperature (K) 


\section{Greek Letters}

$\eta \quad$ Overpotential (V)

$\rho$ Density $\left(\mathrm{kg} / \mathrm{m}^{3}\right)$

$\varepsilon$ Porosity

$\sigma \quad$ Ionic conductivity $(\mathrm{S} / \mathrm{m})$

$\phi \quad$ Phase potential (V)

$v$ Volumetric flow rate $\left(\mathrm{m}^{3} / \mathrm{s}\right)$

$\xi \quad$ Water content of the membrane

$\mu$ Viscosity $(\mathrm{kg} \mathrm{m} / \mathrm{s})$

$\alpha$ Transfer coefficient for the reaction

\section{Introduction}

A fuel cell is an electro-chemical energy device that converts the chemical energy of fuel directly into electricity and heat, with water as a by-product of the reaction. Based on the types of electrolytes used, they are categorized into polymer electrolyte membrane fuel cells (PEMFCs), solid oxide fuel cells (SOFCs), phosphoric acid fuel cells (PAFCs), molten carbonate fuel cells (MCFCs), and direct methanol fuel cells (DMFCs). The polymer exchange membrane fuel cell (PEMFC) is considered to be the most promising candidate for electric vehicles by virtue of its high power density, zero pollution, low operating temperature, quick start-up capability and long lifetime. Polymer exchange membrane fuel cell can also be used in distributed power systems, submarines, and aerospace applications [1].

The single-cell polymer exchange membrane fuel cell consists of a carbon plate, a gas diffusion layer (GDL), a catalyst layer, for each of the anode and the cathode sides, as well as a PEM membrane at the center. Flow channel geometry is of critical importance for the performance of fuel cells containing proton exchange membranes (PEM), but is of less concern for solid oxide fuel cells (SOFC). The reactants, as well as the products, are transported to and from the cell through flow channels. Flow field configurations, including parallel, serpentine, interdigitated, and other combined versions, have been developed.

The performance of the fuel cell system is characterized by current-voltage curve, i.e., (polarization curve). The difference between the open circuit potential of the electrochemical reaction and cell voltage occurs from the losses associated with the operation. The corresponding voltage drop is generally classified into three parts:

1. activation over-potential caused by the electrochemical reactions,

2. ohmic drop across the polymer electrolyte,

3. mass transfer limitations of reactants.

These associated losses dominate over different current density ranges. For low current densities, the activation over- potential is dominant. For high current densities, which are of particular interest for vehicle applications because of higher power density, the mass transfer limitations dominate the losses. For moderate current densities, the ohmic drop across the polymer membrane dominates. Moreover, for high current densities, water starts to exist in liquid form leading to a two-phase transport of reactants to reaction site, which is an additional transport phenomenon of PEM fuel cell operation.

Khazaee and Ghazikhani [2] proposed a complete threedimensional and single phase model for annular-shaped PEM fuel cell to investigate the effect of using different connections between bipolar plate and gas diffusion layer on the performances, current density, and temperature and gas concentration. They found that the cell performance is increased as the number of connections between GDL and bipolar plate increases, but for one connection conditions the effect of changing the location of connection on cell performance is negligibly small. Also they found that the water mole fraction gradually increases along the cell and the maximum of it is near the connections between GDL and bipolar plate.

West and Fuller [3] proposed a two-dimensional numerical analysis of the rib spacing in PEM electrode assemblies on current and water distribution within the cell. The results indicated that increasing the rib width strongly affected the membrane water content before the catalyst utilization is reduced. Therefore, the two-dimensional effect has a significant influence on water management.

Gurau et al. [4] presented a comprehensive model for the entire sandwich of a polymer exchange membrane fuel cell including the gas channels and considered the gas-liquid phases in separate computation domains for transport in the gas distribution channels. It was assumed that the catalyst layer is infinitesimally thin.

Chiang and Chu [5] investigated the effects of transport components on the transport phenomena and performance of PEM fuel cells using a three-dimensional model. The impacts of channel aspect ratio (AR) and GDL thickness were examined. It was found that a flat channel with a small AR or a thin GDL generates more current at low cell voltage due to the merits of better reactant gas transport and liquid water delivery.

Wang et al. [6] developed a two-dimensional numerical model to study the two-phase flow transport in the air cathode of a polymer exchange membrane fuel cell. In this paper, the model encompassed both single- and two-phase regimes corresponding to low and high current densities and was capable of predicting the transition between the two regimes.

Kuo et al. [7] performed numerical simulations to evaluate the convective heat transfer performance and velocity flow characteristics of the gas flow channel design to enhance the performance of proton exchange membrane fuel cells (PEMFCs). Their study has simulated low Reynolds number 
laminar flow in the gas flow channel of a Polymer exchange membrane fuel cell (PEMFC). The heat transfer performance and enhanced gas flow velocity characteristics of four different channel geometries have been considered, namely a conventional straight gas flow channel and a gas flow channel with the three novel periodic patterns geometries. The results indicated that, compared to the conventional gas flow channel, the novel gas flow channels proposed in this study provide a significantly improved convective heat transfer performance and a higher gas flow velocity and, hence, an improved catalysis reaction performance in the catalyst layer.

Berning and Djilali [8] examined the effect of the porosity and thickness of gas diffusion layer in straight channel with three-dimensional model. These polymer exchange membrane fuel cell numerical analysis models contributed to the optimization of component design and operation condition, and to the examination of issues included in present cell. However, these studies calculated internal phenomena in short straight gas channel and one serpentine channel or in small cell, and there are very few researches that evaluated various component shapes of actual size cell under considering realistic calculation time and calculation resource.

Piuleac et al. [9] used a mathematical tool, artificial neural networks, to predict the fuel cells results (the value of the tortuosity and the cell voltage, at a given current density and, therefore, the power) on the basis of several properties that define a Gas Diffusion Layer: Teflon content, air permeability, porosity, mean pore size, hydrophobia level. Their work that based on inverse neural network modeling was able to determine, with small errors, the initial conditions leading to imposed values for characteristics of the fuel cell and the influence of the properties of the gas diffusion layer on the cell performance.

Piuleac et al. [10] used an important tool of Artificial Intelligence for fuel cell researchers to help them to elucidate the processes within the cells, by allowing optimization of materials, cells, stacks, and systems and support control systems. Their model provides good predictions for different values of operating temperatures and potential and, hence, it is the best choice among the study models, recommended to investigate the influence of process variables of polymer exchange membrane fuel cells.

Ubeda et al. [11] used a three-dimensional half-cell model for a $50 \mathrm{~cm}^{2}$ high temperature polyelectrolyte membrane fuel cell (HTPEMFC) in a computational fluid dynamics (CFD) application that it was solved for three different flow channel geometries: 4-step serpentine, parallel and pin-type. Theie model predicts that parallel flow channels present a significant lower performance probably due to the existence of preferential paths which makes the reactant gases not to be well distributed over the whole electrode surface. Also their model predicts mass transfer problems and low limit current densities when the fuel cell is fed with small oxygen flow rates, whereas no differences regarding average flow rates are noticed if it is over increased.

Khazaee and Ghazikhani [12] proposed a complete threedimensional and single phase model for annular-shaped PEM fuel cell to investigate the effect of using different connections between bipolar plate and gas diffusion layer on the performances, current density, and temperature and gas concentration. They found that the cell performance is increased as the number of connections between GDL and bipolar plate increases but for one connection conditions the effect of changing the location of connection on cell performance is negligibly small. Also they found that the water mole fraction gradually increases along the cell and the maximum of it is near the connections between GDL and bipolar plate.

Úbeda et al. [13] designed a good flow channel geometry that can favor a uniform current density profile, hence hypothetically extending fuel cell life. They found that the 4 step serpentine and pin-type geometries distribute the reactants more effectively, obtaining a relatively flat current density map at higher current densities than parallel or interdigitated ones and yielding maximum powers up to $25 \%$ higher when using oxygen as comburent.

In this work, a three-dimensional and single phase CFD model for duct-shaped geometry of PEM fuel cell is presented to investigate the effect of using different connections between bipolar plate and gas diffusion layer on the performances, current density and gas concentration. The objective of the current work is to design a different geometry of the fuel cell and the effect of increasing the number of connections between bipolar plate and gas diffusion layer that it is important to engineers and researchers attempting to develop the optimization of a Fuel cell and the flow modification aspects to enhance the performance.

\section{Numerical Model}

The cathode electrochemical reactions produce a large amount of liquid water at low operating voltages. If the liquid water is not properly removed and accumulates in the pores of the porous layers, it restricts the oxygen transport to the gas diffusion layer and the catalyst layer, thereby reducing the electrochemical reaction rate.

The numerical model for the fuel cell used here includes the anode flow channels, anode gas diffusion layer, anode catalyst layer, proton exchange membrane, cathode catalyst layer, cathode gas diffusion layer, and cathode flow channels. Miniature duct-shaped fuel cells with dimensions of $4.512 \mathrm{~mm} \times 4.512 \mathrm{~mm} \times 12 \mathrm{~mm}$ are considered in this investigation. The gas diffusion layer is $0.3 \mathrm{~mm}$ thick, the catalyst layer is $0.01 \mathrm{~mm}$ thick, and the proton exchange membrane is $0.05 \mathrm{~mm}$ thick.

The geometrical relations in this study are for six different connections between GDL and bipolar plate. The physical 

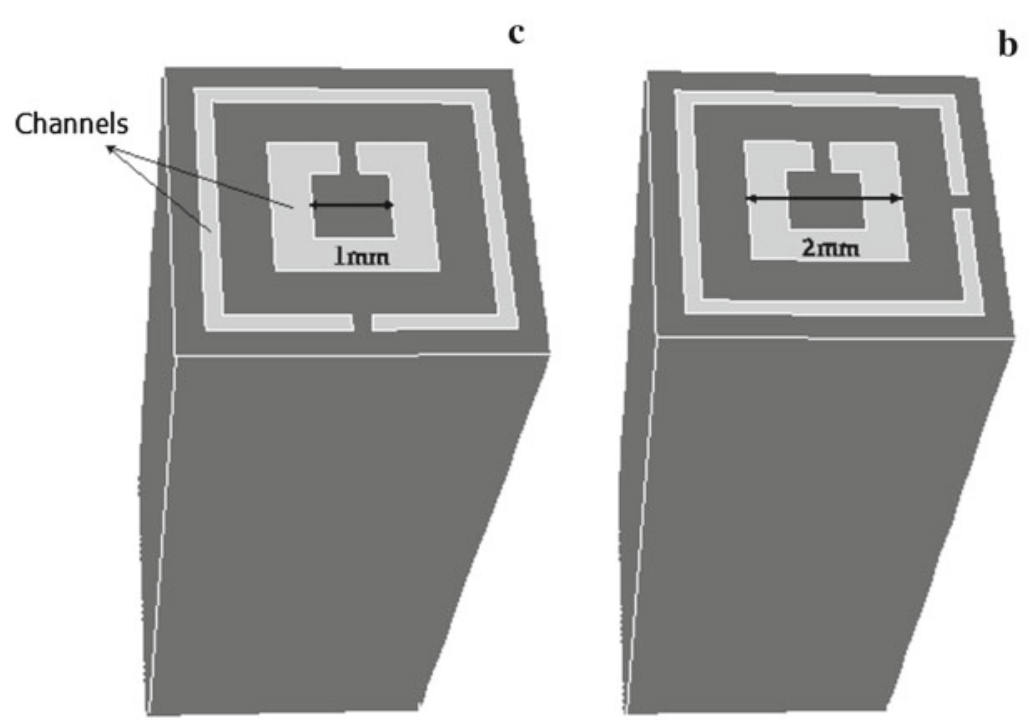

b
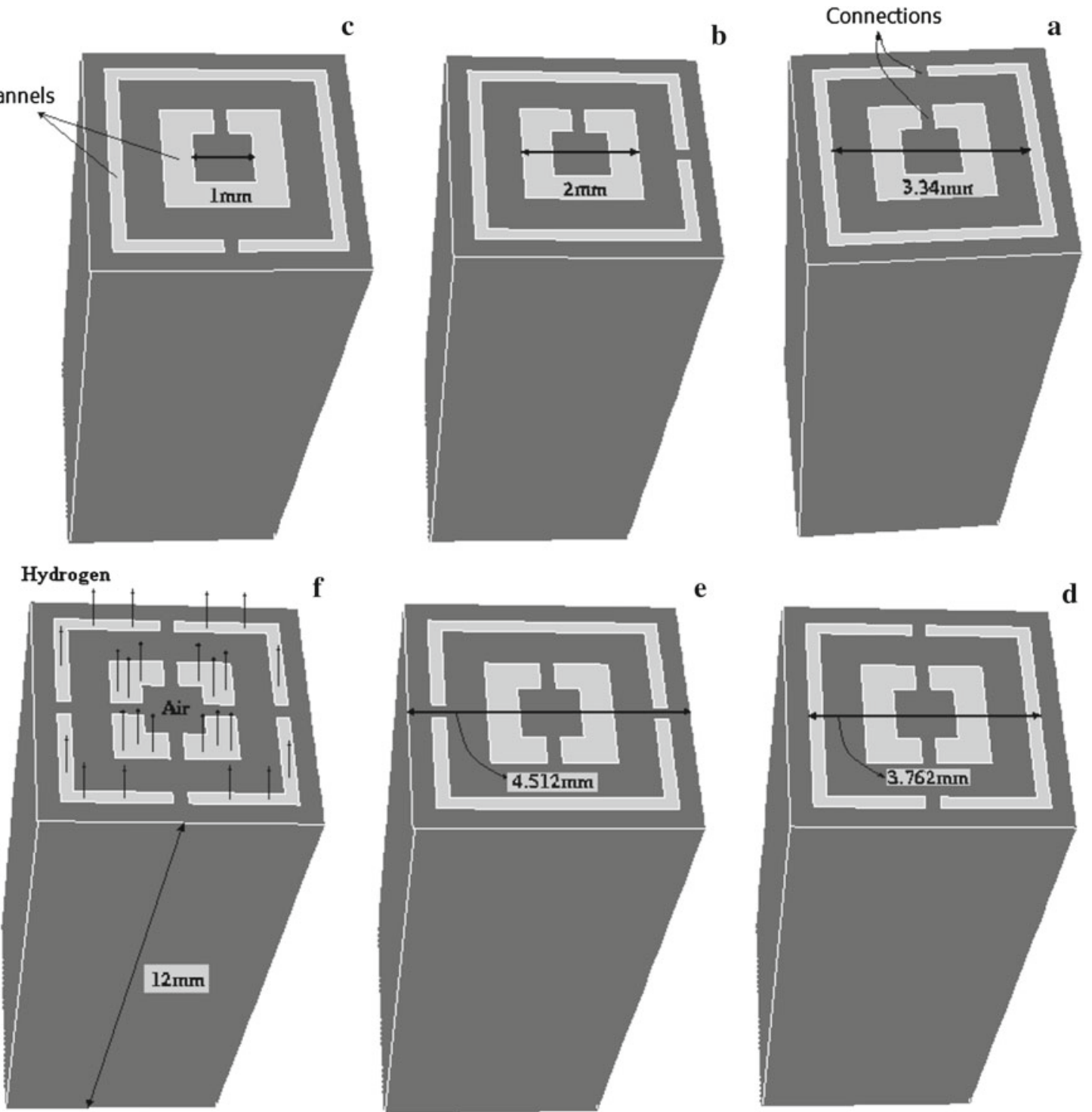

f

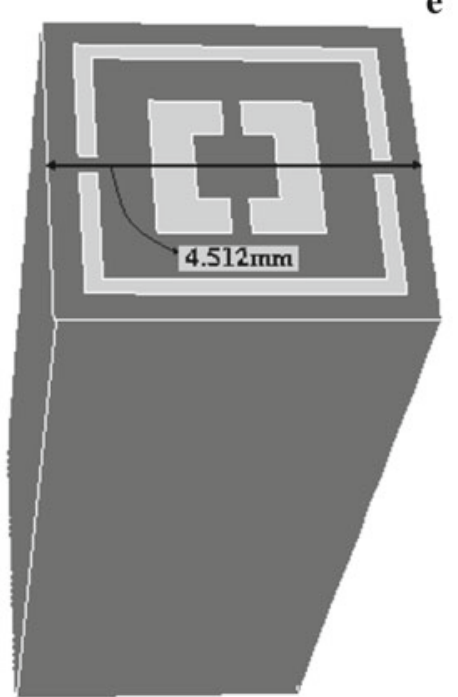

e

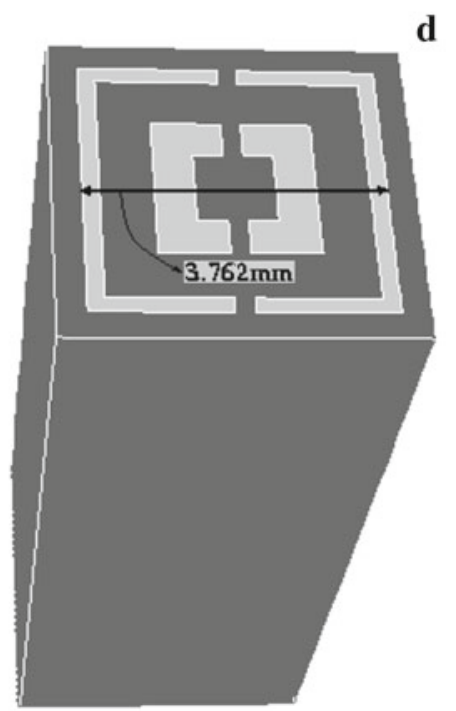

Fig. 1 Computational domain and schematic of duct-shaped polymer exchange membrane fuel cell with a one connection (1), b one connection (2), $\mathbf{c}$ one connection (3), $\mathbf{d}$ two connection (1), $\mathbf{e}$ two connection (2) and $\mathbf{f}$ four connection

problem considered in this paper is the three-dimensional cell model of the polymer exchange membrane fuel cell system as shown in Fig. 1.

The proposed model does not require any internal boundary conditions between the components of PEM Fuel Cell system. The different physical properties and transport parameters are incorporated into a single set of governing equations using a single domain formulation. The model aims to study the electrochemical kinetics, current distribution, reactant flow fields and multi-component transport of oxidizer and fuel streams in a multi-dimensional domain. The assumptions made in developing the model are as follows:
- Ideal gas mixtures

- Incompressible and Laminar flow because low flow velocities and low fuel utilization

- Isotropic and homogeneous porous electrodes, catalyst layers and membrane

- Negligible ohmic resistance at porous electrodes and current collectors

The model assumes that the system is steady; the inlet reactants are ideal gases; the flow is laminar; and the porous layers such as the diffusion layer, catalyst layer and PEM are isotropic. The model includes continuity, momentum and species equations for gaseous species, liquid water transport 
equations in the channels, gas diffusion layers, and catalyst layers, water transport equation in the membrane, electron and proton transport equations. The Bulter-Volumer equation was used to describe electrochemical reactions in the catalyst layers.

The conservation equations of mass, momentum, energy, species and charge are as follows:

$$
\begin{aligned}
& \frac{\partial(\rho \varepsilon)}{\partial t}+\nabla \cdot(\varepsilon \rho \vec{u})=0 \\
& \frac{\partial(\rho \varepsilon \vec{u})}{\partial t}+\nabla \cdot(\varepsilon \rho \vec{u} \vec{u})=-\varepsilon \nabla p+\nabla \cdot(\varepsilon \mu \nabla \vec{u})+S_{u}
\end{aligned}
$$

$$
\begin{aligned}
& \frac{\partial(\rho \vec{u}(E+p))}{\partial t}+\nabla \cdot((E+p) \rho \vec{u} \vec{u}) \\
& \quad=\nabla \cdot\left(\lambda_{\text {eff }} \nabla T-\sum_{k} h_{k} J_{k}+\left(\tau_{\text {eff }} \cdot \vec{u}\right)\right)+S_{h}
\end{aligned}
$$

$\frac{\partial\left(\varepsilon X_{k}\right)}{\partial t}+\nabla \cdot\left(\varepsilon \vec{u} X_{k}\right)=\nabla \cdot\left(D_{k}^{\mathrm{eff}} \nabla X_{k}\right)+S_{k}$

$\nabla \cdot\left(\sigma_{g}^{\text {eff }} \nabla \phi_{\mathrm{e}}\right)+S_{\phi}=0$

where $\vec{u}, X_{k}, h_{k}, \tau_{\text {eff }}, \lambda_{\text {eff }}$ and $\phi_{\mathrm{e}}$ denotes intrinsic velocity vector, molar fraction of $k$ thspecies, enthalpy of species $\mathrm{k}$, effective stress tensor which can be ignored due to the low velocity of laminar gas flow, effective thermal conductivity in a porous material consisting of the electrode solid matrix and gas and electrolyte phase potential, respectively. The corresponding source terms $\left(S_{k}, S_{\phi}, S_{u}, S_{h}\right)$ treating the electrochemical reactions and porous media are presented in Table 1.

$\lambda_{\mathrm{eff}}=\varepsilon \lambda_{\mathrm{f}}+(1-\varepsilon) \lambda_{\mathrm{s}}$,

where $\lambda_{\mathrm{s}}$ is the thermal conductivity of the electrode solid matrix and $\lambda_{\mathrm{f}}$ is the thermal conductivity of the gas, which can be expressed as a function of temperature:

$\lambda_{\mathrm{f}}=a_{0}+a_{1} T+a_{2} T^{2}+a_{3} T^{3}$
It is of benefit to further explain the corresponding diffusivities of the governing equations. The diffusivities for species concentration equations and ionic conductivity for membrane phase potential equation are modified using Bruggman correlation to account for porous electrodes, which can be expressed as:

$D_{k}^{\mathrm{eff}}=\varepsilon_{m}^{1.5} D_{k}$

$\sigma_{\mathrm{e}}^{\mathrm{eff}}=\varepsilon_{m}^{1.5} \sigma_{\mathrm{e}}$

It is worth further explaining the mole fraction of oxygen appearing in Eq. (4) because oxygen is a gaseous species in the cathode flow channel and gas-diffusion electrode but becomes a species dissolved in the electrolyte in the catalyst layer and membrane regions. Our definition is given by

$X_{k}= \begin{cases}C_{k}^{g} / C_{\text {tot }} & \text { in gas } \\ C_{k}^{e} / C_{\text {tot }} & \text { in electrode }\end{cases}$

where $C_{k}$ is the molar concentration of species $k$ and superscripts $g$ and e denote the gas and the electrolyte phases, respectively. Thus, $X_{k}$ is a true mole fraction in the gas phase but is a pseudo mole fraction when species $k$ is in the dissolved form. In addition, there is a discontinuity in the value of $X_{k}$ at the interface between the gas-diffusion electrode and the catalyst layer due to the following thermodynamic relation

$C_{k}^{\mathrm{e}, \mathrm{sat}}=\frac{R T}{H} C_{k}^{g}$,

where $H$ is the Henry's law constant equal to $2 \times 10^{5}$ atm $\mathrm{cm}^{3} / \mathrm{mol}$ for oxygen in the membrane.

Either generation or consumption of chemical species $k$ and the creation of electric current occurs only in the active catalyst layers where electrochemical reactions take place. The $S_{k}$ and $S_{\phi}$ terms are, therefore, related to the transfer current between the solid matrix and the membrane phase inside each of the catalyst layers. These transfer currents at anode and cathode can be expressed as follows

$j_{a}=a j_{0, a}^{\mathrm{ref}}\left(\frac{X_{\mathrm{H}_{2}}}{X_{\mathrm{H}_{2}, \mathrm{ref}}}\right)^{1 / 2}\left(\frac{\alpha_{a}+\alpha_{c}}{R T} . F . \eta\right)$

Table 1 Source terms

\begin{tabular}{lllll}
\hline & $S_{v}$ (momentum) & $S_{k}$ (species) & $\mathrm{S}_{\phi}$ (phase potential) & $\mathrm{S}_{h}$ (energy) \\
\hline Gas channels & 0 & 0 & 0 & 0 \\
Backing layers & $-\frac{\mu}{k} \varepsilon^{2} \vec{u}$ & 0 & 0 & 0 \\
& & $-\frac{j_{a}}{2 F} \frac{\rho}{\varepsilon_{m} \varepsilon_{m c}}:$ anode $\mathrm{H}_{2}$ & $-\frac{|j a|}{2 F} T|\Delta s|+\left|j_{c} \eta_{c}\right| f$ \\
Catalyst layers & $-\frac{\mu}{k} \varepsilon^{2} \vec{u}$ & $-\frac{j c}{F} \frac{\rho}{\varepsilon_{m} \varepsilon_{m c}}:$ cathode $\mathrm{O}_{2}$ & or cathode \\
& $-\frac{n_{\mathrm{d}}}{F} j_{a} \frac{\rho}{\varepsilon_{m} \varepsilon_{m c}}:$ anode $\mathrm{H}_{2} \mathrm{O}$ & $\rho$ & 0 \\
Membrane & 0 & $j$ & 0 & for anode \\
\hline
\end{tabular}


$j_{c}=-a j_{0, c}^{\mathrm{ref}}\left(\frac{X_{\mathrm{O}_{2}}}{X_{\mathrm{O}_{2}, \mathrm{ref}}}\right)^{1 / 2}\left(-\frac{\alpha_{c} \cdot F}{R T} \cdot \eta\right)$.

The above kinetics expressions are derived from the general Bulter-Volmer equation based on the facts that the anode exhibits fast electrokinetics and hence a low surface overpotential to justify a linear kinetic rate equation, and that the cathode has relatively slow kinetics to be adequately described by the Tafel equation. In Eqs. (12) and (13), the surface overpotential, $\eta(x, y)$, is defined as

$\eta(x, y)=\phi_{\mathrm{s}}-\phi_{\mathrm{e}}-V_{\mathrm{oc}}$,

where $\phi_{\mathrm{s}}$ and $\phi_{\mathrm{e}}$ stand for the potentials of the electronically conductive solid matrix and electrolyte, respectively, at the electrode electrolyte interface. $V_{\text {oc }}$ is the reference open-circuit potential of an electrode. $V_{\mathrm{oc}}$ is the reference open-circuit potential of an electrode. It is equal to zero on the anode but is a function of temperature on the cathode namely

$V_{\mathrm{oc}}=0.0025 T+0.2329$,

where $T$ is in Kelvin and $V_{\mathrm{oc}}$ is in volts. Notice that $V_{\mathrm{oc}}$ is not the true open-circuit potential of an electrode, which would then depend upon reactant concentrations according to the Nernst equation.

Equation (12), which is a rewritten form of the Nernst equation, precisely describes the effect of decreasing transfer current under hydrogen dilution. The dependence of the cathodic exchange current density on temperature can be fitted as

$\frac{i_{0}(T)}{i_{0}(353 K)}=\exp (0.014189(T-353))$.

The species diffusivity, $D_{k}$, varies in different subregions of the polymer exchange membrane fuel cell depending on the specific physical phase of component $\mathrm{k}$. In flow channels and porous electrodes, species $k$ exists in the gaseous phase, and thus the diffusion coefficient takes the value in gas, whereas species $k$ is dissolved in the membrane phase within the catalyst layers and the membrane, and thus takes the value corresponding to dissolved species, which is usually a few orders of magnitude lower than that in gas. In addition, the diffusion coefficient is a function of temperature and pressure.

$D(T)=D_{0}\left(\frac{T}{T_{0}}\right)^{3 / 2}\left(\frac{p_{0}}{p}\right)$

The proton conductivity in the membrane phase has been correlated as

$\sigma_{\mathrm{e}}(T)=100 \exp \left[1,268\left(\frac{1}{303}-\frac{1}{T}\right)\right](0.005139 \xi$ $-0.00326)$,

where the water content in the membrane, $\xi$, depends on the water activity, $a$, according to the following fit of the exper- imental data

$\xi= \begin{cases}0.043+17.18 a-39.85 a^{2}+36 a^{3} & 0 \prec a \leq 1 \\ 14+1.4(a-1) & 1 \leq a \leq 3\end{cases}$

The water activity is in turn calculated by

$a=\frac{X_{\mathrm{H}_{2} \mathrm{O} p}}{p_{\mathrm{sat}}}$,

where the saturation pressure of water vapor can be computed from the following empirical equation

$$
\ln \left(p^{\text {sat }}\right)=70.43464-\frac{7362.698}{T}+0.006952 T-9 \ln (T) \text {. }
$$

In a fuel cell system, the inlet flow rates are generally expressed as stoichiometric ratios of inlet streams based on a reference current density. The stoichiometric ratios inlet streams are given by the following equations.

$S^{\text {anode }}=C_{\mathrm{H}_{2}} v^{\text {anode }} \frac{2 F}{I_{\text {ref }} A}$

$S^{\text {cathode }}=C_{\mathrm{O}_{2}} v^{\text {cathode }} \frac{4 F}{I_{\mathrm{ref}} A}$.

Water transport through the polymer electrolyte membrane has been investigated by several researchers in different aspects. Most interesting studies in this area include the determination of water diffusion coefficient [14] and water drag coefficient by Zawodzinski et al. [15] and investigating the diffusion of water in Nafion membranes by Motupally et al.[16].

The electro-osmotic drag coefficient is defined as the number of water molecules transported by each hydrogen proton $H^{+}$. The electro-osmotic drag coefficient can be expressed with the following equation:

$n_{\mathrm{d}}=\frac{2.5 \xi}{22}$

The diffusion coefficient of water in Polymer Membrane is also highly dependent on the water content of the membrane. The relation is given as:

$D_{w}^{m}=\left\{\begin{array}{cc}3.1 \times 10^{-7} \xi(\exp (0.28 \xi)-1) \exp (-2346 / T) & 0<\xi \prec 3 \\ 4.17 \times 10^{-8} \xi(1+161 \exp (-\xi)) \exp (-2346 / T) & \text { otherwise }\end{array}\right\}$

Once the electrolyte phase potential is determined in the membrane, the local current density along the axial direction can be calculated as follows

$I(y)=-\left.\sigma_{\mathrm{e}}^{\mathrm{eff}} \frac{\partial \phi_{\mathrm{e}}}{\partial x}\right|_{x=I F}$, 
Table 2 Electrochemical and transport properties

\begin{tabular}{lll}
\hline Description & Unit & Value \\
\hline Anode reference exchange current density & $\mathrm{A} / \mathrm{m}^{3}$ & $1.5 \mathrm{e} 9$ \\
Cathode reference exchange current density & $\mathrm{A} / \mathrm{m}^{3}$ & $4,000,000$ \\
Anode transfer coefficient & & 2 \\
Cathode transfer coefficient & & 2 \\
Faraday constant & $\mathrm{C} / \mathrm{mol}$ & 96,487 \\
$\mathrm{H}_{2}$ Diffusivity & $\mathrm{m}^{2} / \mathrm{s}$ & $3 \mathrm{e}-5$ \\
$\mathrm{O}_{2}$ Diffusivity & $\mathrm{m}^{2} / \mathrm{s}$ & $3 \mathrm{e}-5$ \\
$\mathrm{H}_{2} \mathrm{O}$ Diffusivity at anode & $\mathrm{m}^{2} / \mathrm{s}$ & $3 \mathrm{e}-5$ \\
$\mathrm{H}_{2} \mathrm{O}$ Diffusivity at cathode & $\mathrm{m}^{2} / \mathrm{s}$ & $3 \mathrm{e}-5$ \\
Anode tackling layer porosity & & 0.5 \\
Cathode backing layer porosity & & 0.5 \\
Permeability of anode backing layer & $\mathrm{m}^{2}$ & $\mathrm{e}-12$ \\
Permeability of cathode backing layer & $\mathrm{m}^{2}$ & $\mathrm{e}-12$ \\
Equivalent weight of membrane & $\mathrm{kg} / \mathrm{mol}$ & 1.1 \\
\hline
\end{tabular}

Table 3 Operational parameters

\begin{tabular}{lll}
\hline Description & Unit & Value \\
\hline Reference average current density & $\mathrm{A} / \mathrm{cm}^{2}$ & 1.0 \\
Anode inlet velocity & $\mathrm{m} / \mathrm{s}$ & 0.5 \\
Cathode inlet velocity & $\mathrm{m} / \mathrm{s}$ & 1 \\
Anode inlet pressure & $\mathrm{Atm}$ & 1 \\
Cathode inlet pressure & $\mathrm{Atm}$ & 1 \\
Cell temperature & $\mathrm{C}^{*}$ & 70 \\
Anode inlet molar concentration & & \\
Hydrogen & $\mathrm{mol} / \mathrm{m}^{3}$ & 35.667 \\
Oxygen & $\mathrm{mol} / \mathrm{m}^{3}$ & 0 \\
Water vapor & $\mathrm{mol} / \mathrm{m}^{3}$ & 16.121 \\
Cathode inlet molar concentration & & \\
Hydrogen & $\mathrm{mol} / \mathrm{m}^{3}$ & 0 \\
Oxygen & $\mathrm{mol} / \mathrm{m}^{3}$ & 7.51 \\
Water vapor & $\mathrm{mol} / \mathrm{m}^{3}$ & 16.121 \\
\hline
\end{tabular}

where IF means the interface between the membrane and cathode catalyst layer. The average current density is then determined by

$I_{\mathrm{avg}}=\frac{1}{L} \int_{0}^{L} I(y) \mathrm{d} y$,

where $L$ is the cell length.

There are natural boundary conditions of zero-flux prescribed everywhere other than the inlet and outlets of the flow channels. The boundary conditions prescribed at the inlets of the gas channels are:

$$
\begin{array}{|l|l|}
\hline u_{\text {in }}^{\text {anode }}=u_{a}^{0} & u_{\text {in }}^{\text {cathode }}=u_{c}^{0} \\
C_{\mathrm{H}_{2}}^{\text {anode, in }}=C_{\mathrm{H}_{2}}^{0} & C_{\mathrm{O}_{2}}^{\text {cathode, in }}=C_{\mathrm{O}_{2}}^{0} \\
C_{\mathrm{H}_{2} \mathrm{O}}^{\text {anode, in }}=C_{\mathrm{H}_{2} \mathrm{O}}^{0, a} & C_{\mathrm{H}_{2} \mathrm{O}}^{\text {cathode, in }}=C_{\mathrm{H}_{2} \mathrm{O}}^{0, c} \\
\hline
\end{array}
$$

A mesh with 498,592 nodes was found to provide required spatial resolution for different channel geometry. The solution is considered to be converged when the difference between successive iterations is less than $10^{-7}$ for all variables.

The electrochemical and transport parameters used in these simulations are summarized in Table 2, and the operational parameters are presented in Table 3. 
Fig. 2 Comparison between results of this paper and results of Miansari et al. [17]

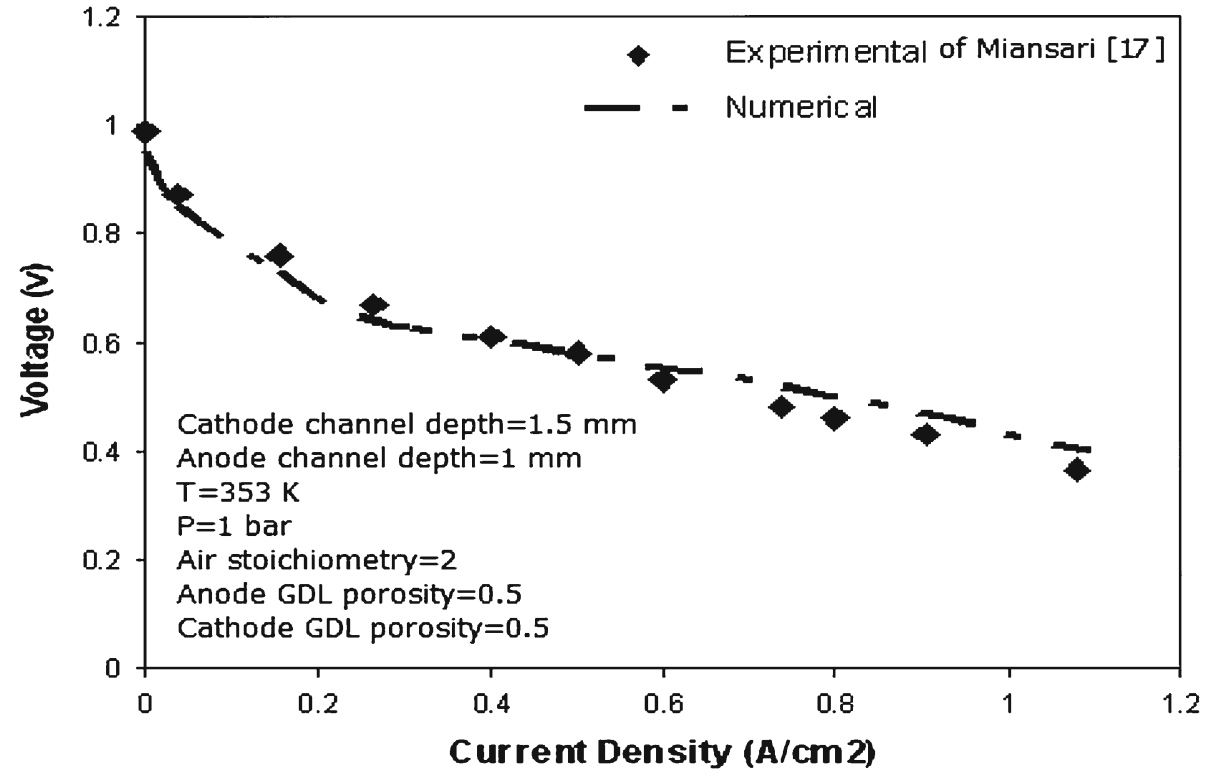

Fig. 3 Variation of cell performance with a one connection (1), b one connection (2), c one connection (3), $\mathbf{d}$ two connection (1), e two connection (2) and $\mathbf{f}$ four connection

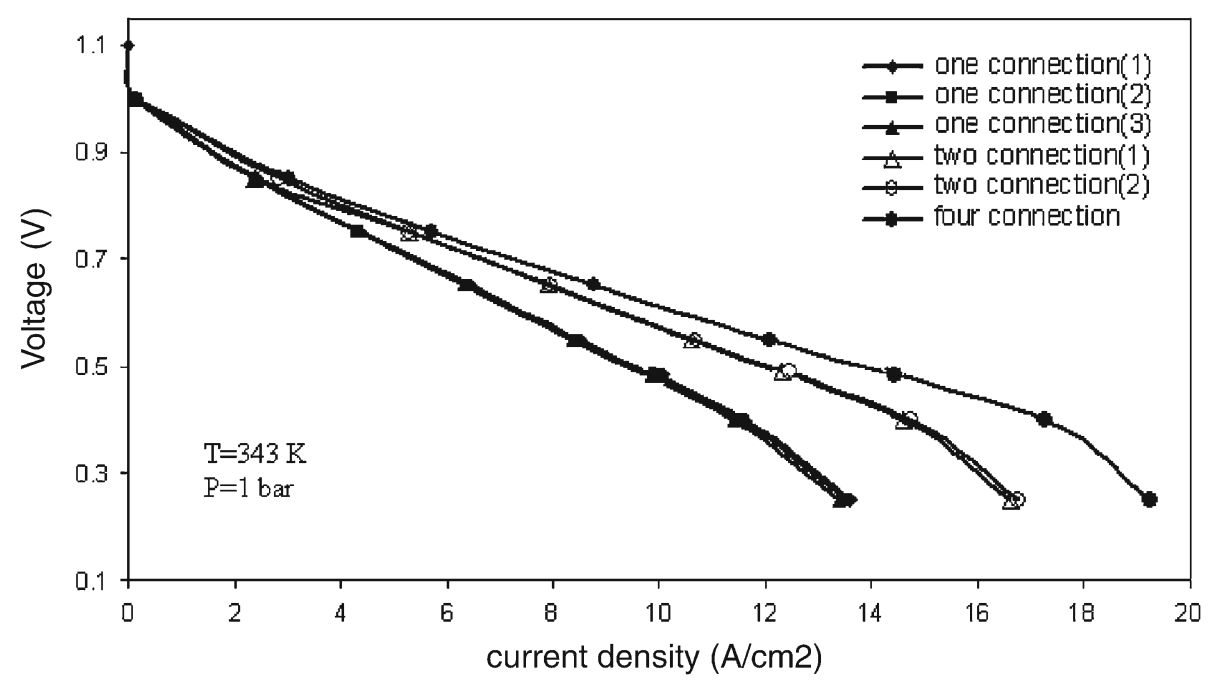

\section{Results and Discussion}

In order to show that the program in this study can handle the cell performance of a polymer exchange membrane fuel cell, we apply the present method to solve the whole of a polymer exchange membrane fuel cell as described in Miansari and others' paper [17]. The physical parameters and properties of the fuel cell are listed in Fig. 2. The mesh employed for the comparison with the reference was $241 \times$ $74 \times 25$. The steady-state solution is obtained by the numerical procedure as mentioned in the previous section. As shown in Fig. 2, the result of the present predictions of the polarization curve agreeing fairly closely with Miansari and others' predictions [17] gives one confidence in the use of the present program.
Figure 3 shows the polarization curves of the duct-shaped fuel cell for different channels geometry with six connections between bipolar plate and gas diffusion layer to investigate the influence of the internal flow modification on the overall cell performance. It shows in Fig. 3 that the effect of the number of connections between GDL and bipolar plate on the cell performance is significant at low operating voltage conditions. However, at high operating voltage conditions, the influence of the connections on the $I-V$ curve is negligibly small. It is also observed that the cell performance is increased as the number of connections between GDL and bipolar plate increases, but for one connection conditions the effect of changing the location of connection on cell performance is negligibly small. This is due to the increase of concentration gradient with increasing the number of gas 

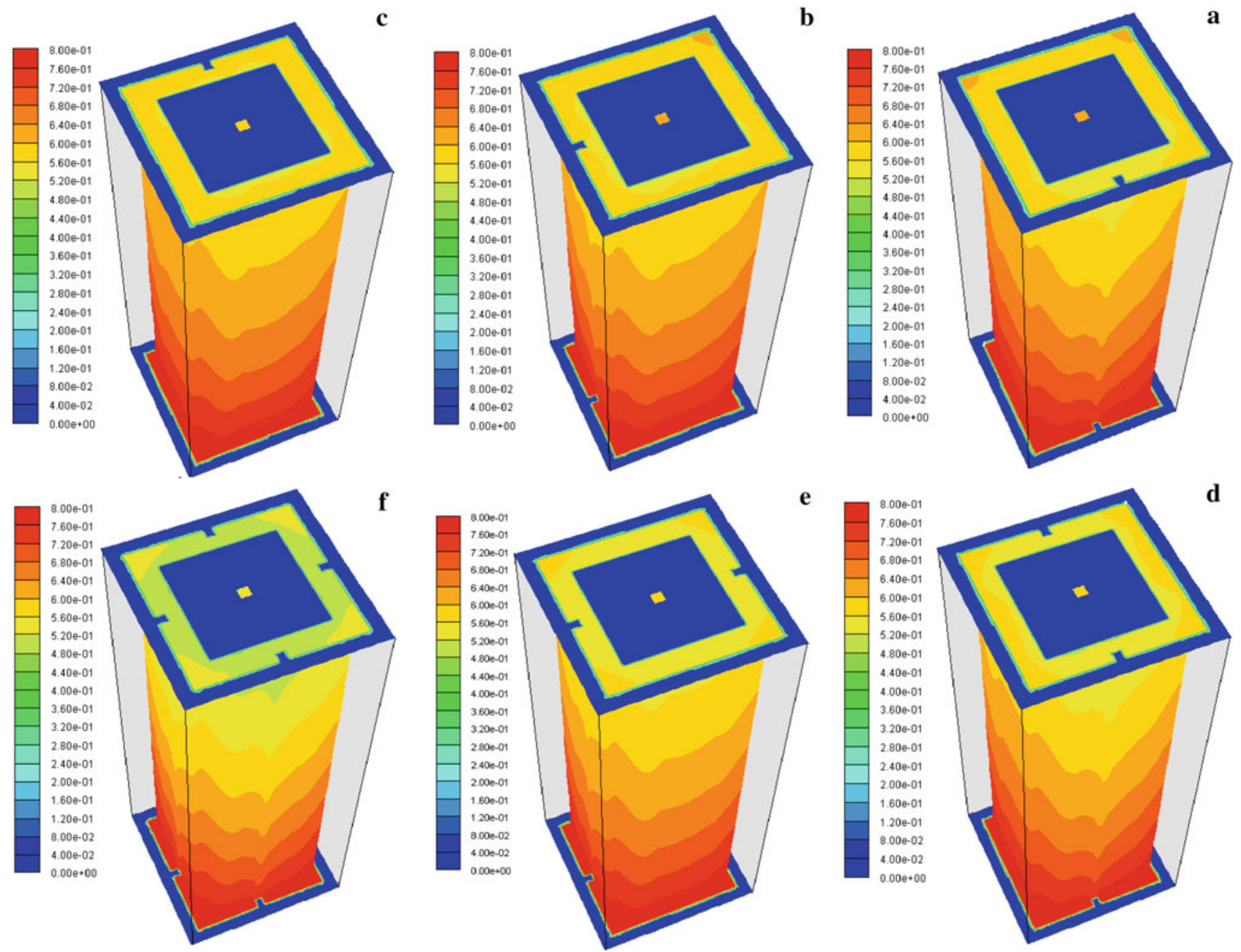

Fig. 4 Hydrogen mass fraction distribution in the anode side channel at $V=0.4 \mathrm{~V}$ with a one connection (1), b one connection (2), c one connection (3), $\mathbf{d}$ two connection (1), e two connection (2) and $\mathbf{f}$ four connection

channels, which in turn, results in a higher mass transfer to the catalyst layer. Therefore, a larger current density takes place.

The hydrogen mass fraction distribution in the anode side channel is shown in Fig. 4 for six different conditions of connection between GDL and bipolar plate for electron transformation at the operating voltage of $0.4 \mathrm{~V}$. It is seen that the mass fraction of hydrogen decreases along the channel due to the consumption and reaction of the hydrogen at catalyst layer. Results show that the mass fraction of the hydrogen decreases as the number of connection increases. This means that the consumption of the fuel gases increases as the gas channels increases. It is clear that the concentration of hydrogen is at lower value near the connection due to more fuel gas forced into and passing through the gas diffusion layer. Also it is shown that in one connection (1), consumption of hydrogen is higher than one connection (2), (3) and concentration contours of hydrogen is unsymmetrical but for two connec- tions (1), (2) and four connection conditions concentration contours of hydrogen is symmetrical.

Figure 5 shows the mass fraction contours of oxygen, respectively, obtained at $V=0.4 \mathrm{~V}$ for six different conditions of connection between GDL and bipolar plate in the cathode side. As shown in Fig. 5, the oxygen mass fraction decreases along the channel due to the consumption of oxygen species within the catalyst layer. Results show that the mass fraction of the oxygen decreases as the number of connection increases, but it is clear that the reduction of oxygen for one connection (1) condition is more than one connection (2), (3). However, as shown in this figure, the reduction of oxygen concentration along the channel is not instantly sensed at the GDL/CL boundary, because the concentration of oxygen at the catalyst layer is balanced by the oxygen that is being consumed and the amount of oxygen that diffuses towards the catalyst layer, driven by the concentration gradient. As a result, a more uniform profile for the oxygen concentration 

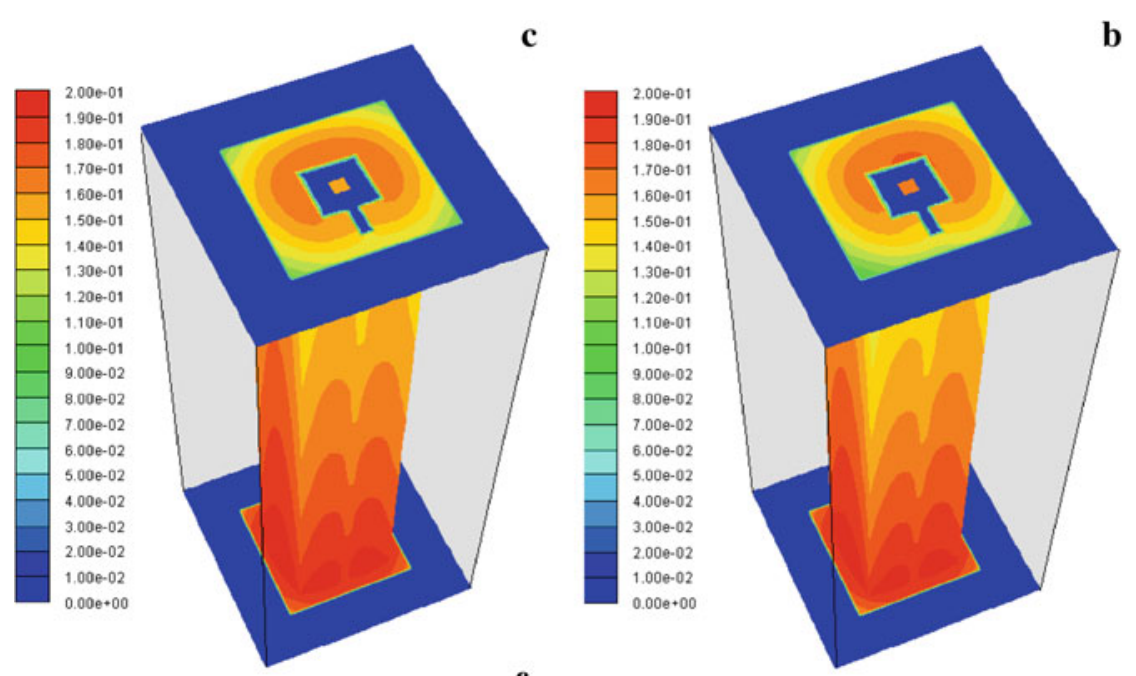

b
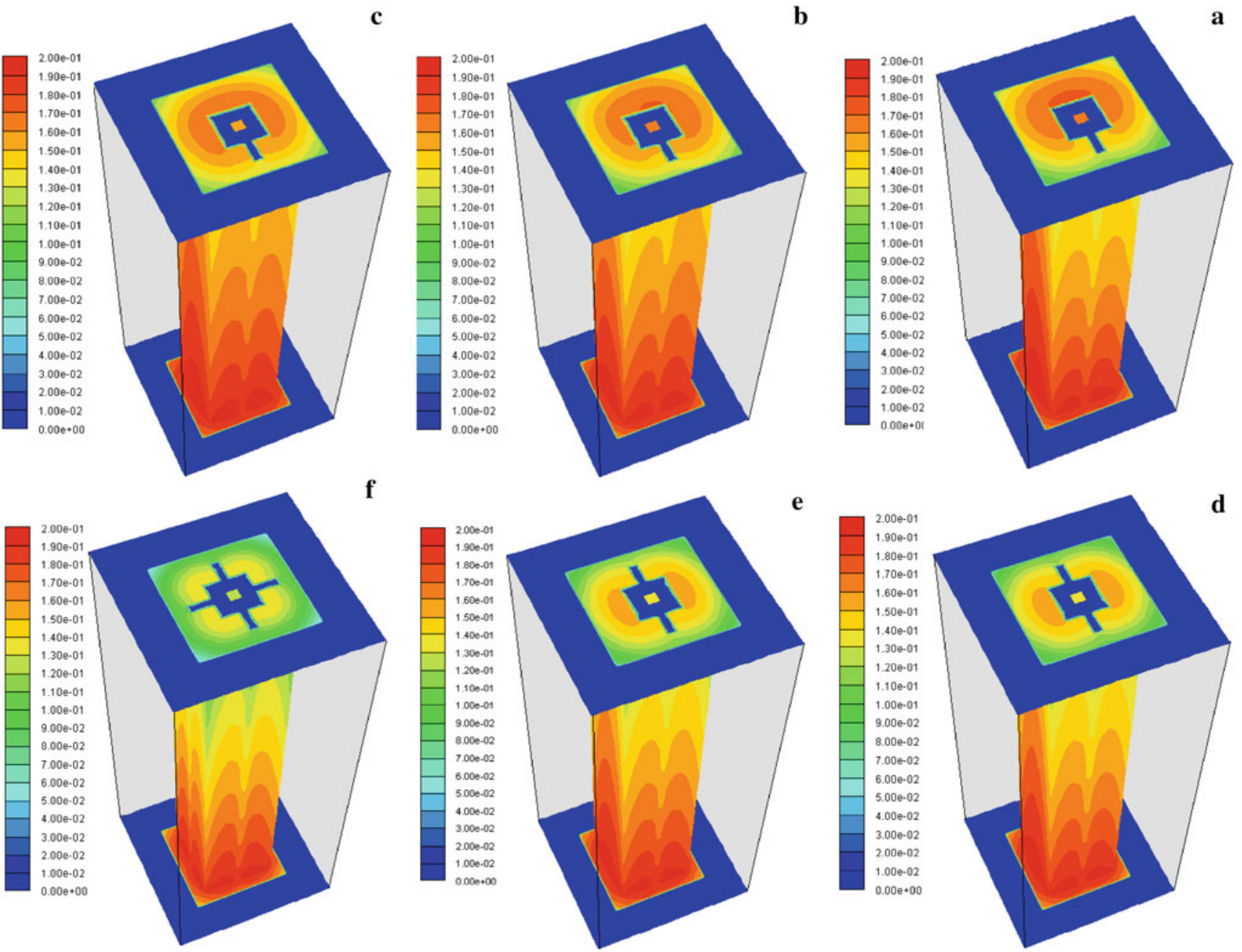

Fig. 5 Oxygen mass fraction distribution in the cathode side channel at $V=0.4 \mathrm{~V}$ with a one connection (1), b one connection (2), c one connection (3), $\mathbf{d}$ two connection (1), e two connection (2) and $\mathbf{f}$ four connection

is read when the number of connection between GDL and bipolar plate increases. Also the decrease in mass fraction of the oxygen along the cathode side is higher than for the hydrogen in anode side due to the smaller diffusivity of the oxygen.

The water molar fraction distribution in the cell is shown in Fig. 6 at $V=0.4 \mathrm{~V}$ for six different connections between GDL and bipolar plate. As shown in Fig. 6, water molar fraction increases along the channel due to (1) the water production by oxygen consumption at the catalyst layer and (2) the net water transfer from the anode side through the membrane toward the cathode side. However, the magnitude of water molar fractions is higher at cathode catalyst layer than the anode catalyst layer and when the number of connections between GDL and bipolar plate increases due to increase in the number of connections, the chemical reaction at cathode catalyst layer enhances and the current density decreases. Also it is shown that for one connection conditions, water molar fraction is unsymmetrical but by increasing the number of connections, symmetrical condition of water mole fraction obtained.

Figure 7 shows the influence of the internal flow modification on the distribution of temperature at $0.4 \mathrm{~V}$ cell voltage for six different connections between GDL and bipolar plate. It is clear that the temperature gradually increases along the cell because of moving the more fuel gas into the gas diffusion layer to enhance the chemical reaction at the catalyst layer. It can be seen that the maximum temperature of the cell is at the cathode catalyst layer that it is due to the maximum heat generation at the cathode side catalyst layer. Also Fig. 7 shows a depression region around the location of the connections between GDL and bipolar plate. This depression region is caused by (1) increasing the traversed distance of gases on the surface, which decreases the temperature of them and (2) formation more water vapor at this region and condensation of them. It is clear that the maximum temperature occurred in 

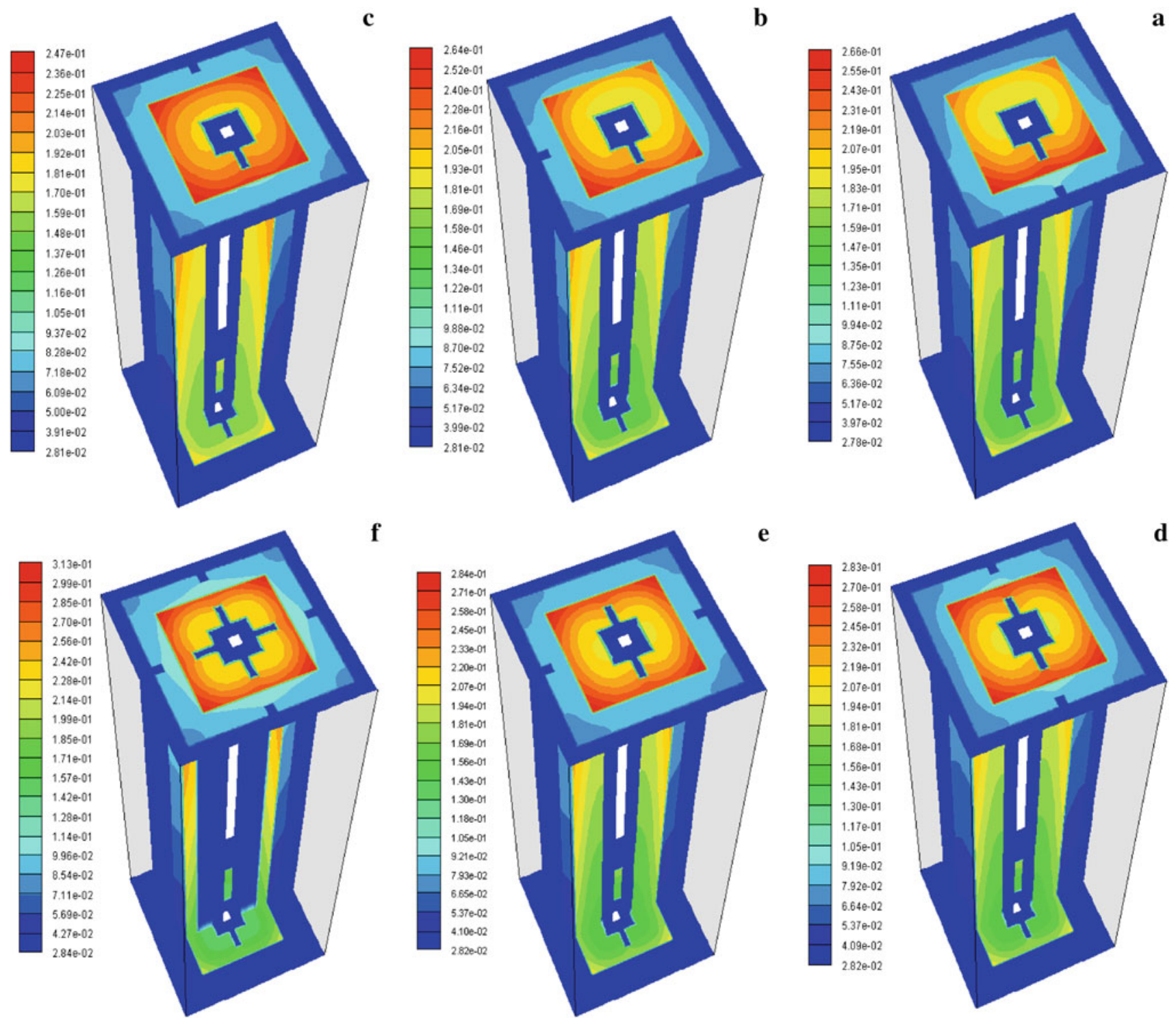

Fig. 6 water mole fraction distribution in the cell at $V=0.4 \mathrm{~V}$ with a one connection (1), b one connection (2), $\mathbf{c}$ one connection (3), d two connection (1), e two connection (2), $\mathbf{f}$ four connection

the cell, decreased by increasing the number of connections between gas diffusion layer and bipolar plate.

Figure 8 shows the local current density distribution at the cathode side catalyst layer at $0.4 \mathrm{~V}$ cell voltage for six different connections between GDL and bipolar plate. It is clear that the current density is higher at the connections between GDL and bipolar plate that these peak regions of the distribution of the local current density are caused by the transverse installation of the connections. This phenomenon means that better cell performance is achieved around the connections. This is due to the fact that the fuel gas is blocked by the connections installed in the flow channel, and more fuel gas is forced into and passes through the GDL, which enhances the chemical reaction at the catalyst surface.
It can be seen that the current density distribution is uniform when the connections between GDL and bipolar plate increase. Also it is clear that the maximum of local current density decreased by increasing the number of connections. But the magnitude of current density is at lower value when the connections of anode and cathode sides are at similar direction due to the deduction of passing distance of the electrons.

The effect of relative humidity on the performance of a Duct-shaped PEM fuel cell with four connections between GDL and bipolar plate at cell voltage of $0.4 \mathrm{~V}$ is shown in Fig. 9. It is obvious that a higher relative humidity of inlet gases leads to a higher performance (voltage) at the cell due to increasing the performance of the membrane of the cell 

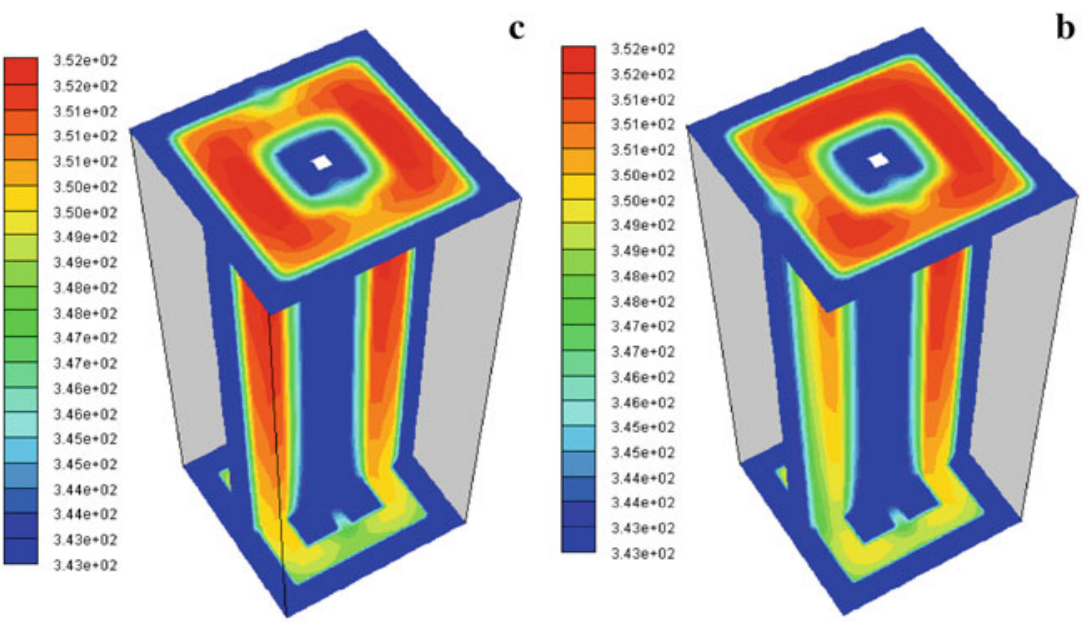

b

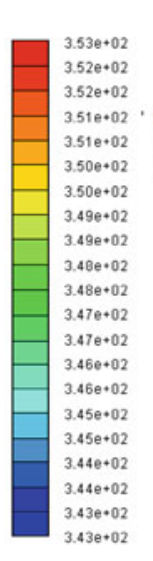

a

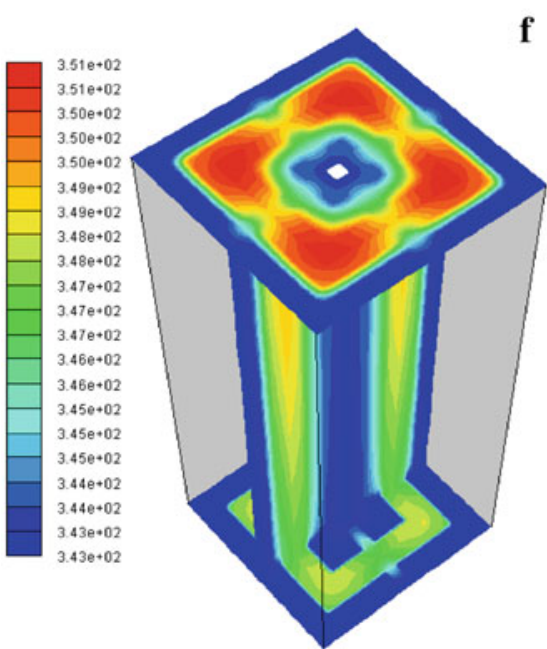

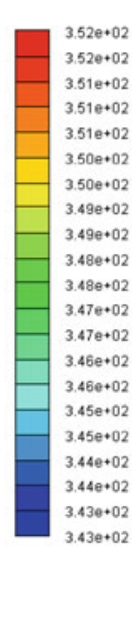
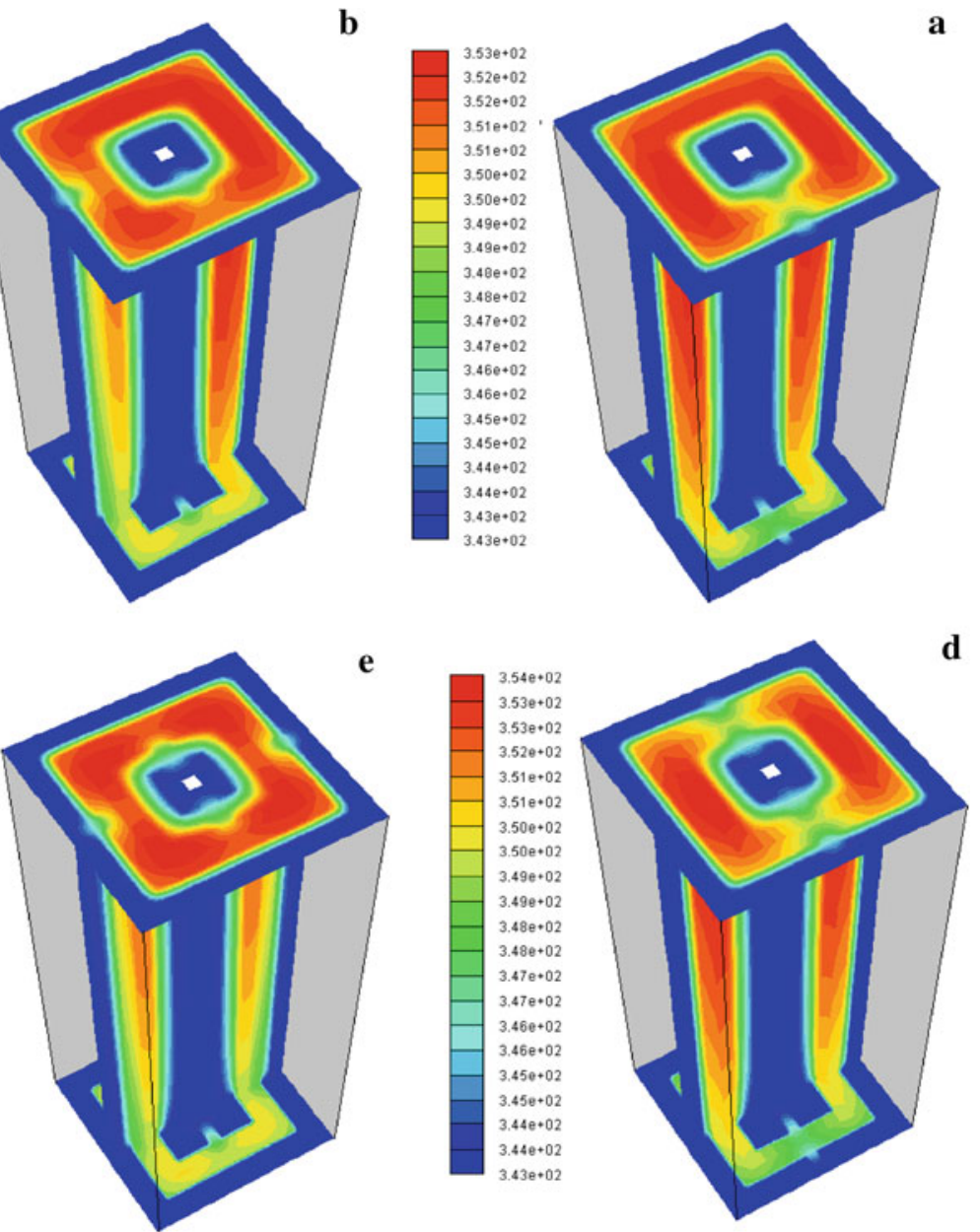

Fig. 7 Temperature distribution in the cell at $V=0.4 \mathrm{~V}$ with a one connection (1), b one connection (2), c one connection (3), d two connection (1), e two connection (2), $\mathbf{f}$ four connection

for exchanging the protons at this condition. Also in Fig. 9, it is clear that the effect of the relative humidity on the cell performance is significant at low operating voltage conditions. However, at high operating voltage conditions, the influence of relative humidity on the $I-V$ curve is negligibly small.

\section{Conclusion}

A complete three-dimensional and single phase model for duct-shaped PEM fuel cell was used to investigate the effect of using different connections between bipolar plate and gas diffusion layer on the performances, current density, and temperature and gas concentration. The complete three-dimensional model for PEM fuel cells based on the two-fluid method was numerically solved with constant-temperature boundary condition at surfaces of anode and cathode current collectors. It has been found that
1. The calculated results are in good agreement with the experimental data.

2. The cell performance is increased as the number of connections between GDL and bipolar plate increases.

3. The water mole fraction gradually increases along the cell and the maximum of it is near the connections between GDL and bipolar plate.

4. When the number of connections between GDL and bipolar plate increases, consumption of hydrogen and oxygen and production of water increases.

5. There is a depression region in temperature distribution around the location of the connections between GDL and bipolar plate that this depression region is caused by increasing the traversed distance of gases on the surface.

6. The maximum of local current density decreased by increasing the number of connections and the magnitude of current density is at lower value when the connections of anode and cathode sides are at similar direction. 

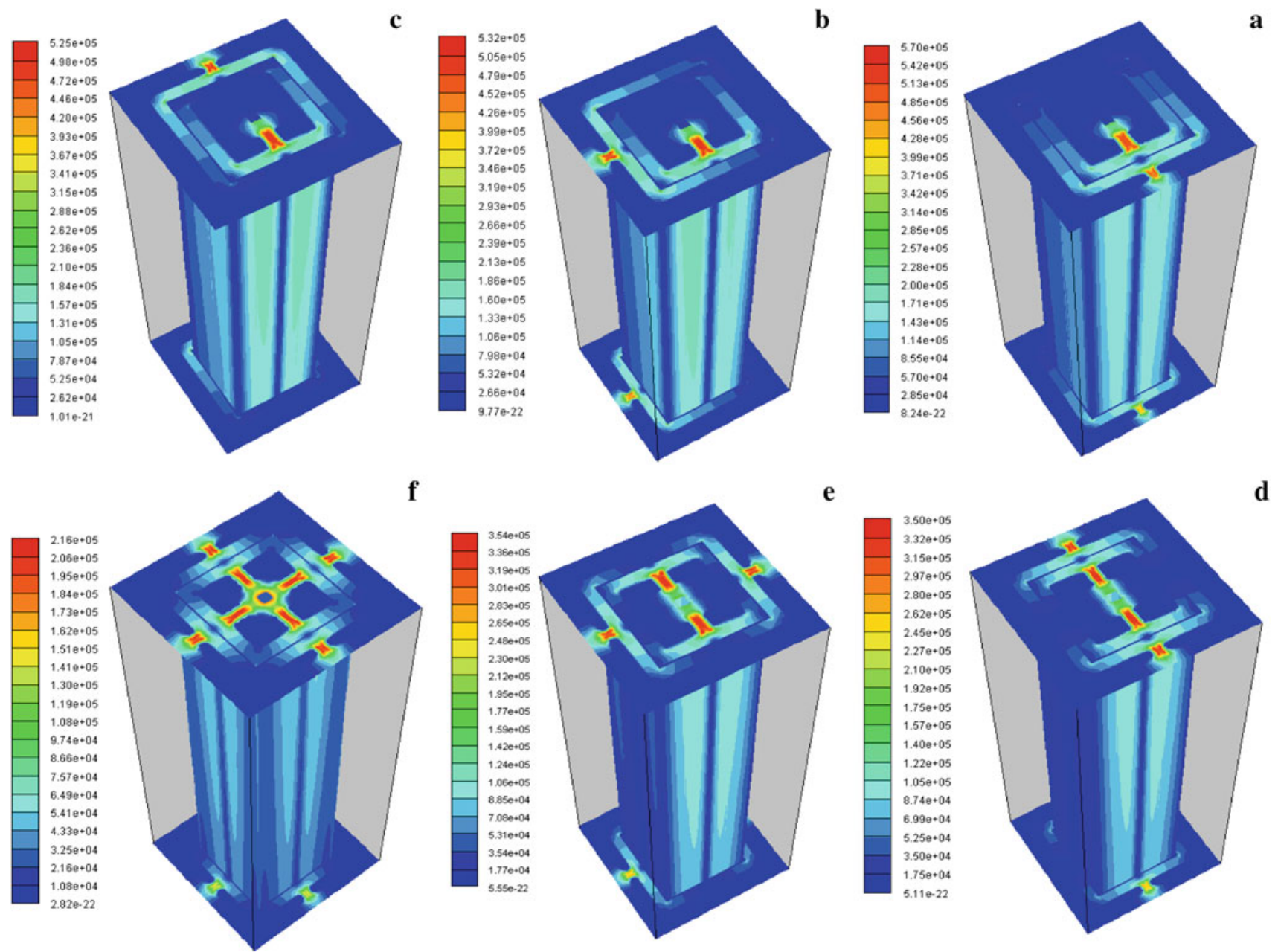

Fig. 8 Current density distribution at the cathode side catalyst layer for $V=0.4 \mathrm{~V}$ with a one connection (1), b one connection (2), $\mathbf{c}$ one connection (3), $\mathbf{d}$ two connection (1), e two connection (2), $\mathbf{f}$ four connection

Fig. 9 Effect of relative humidity on variation of cell performance

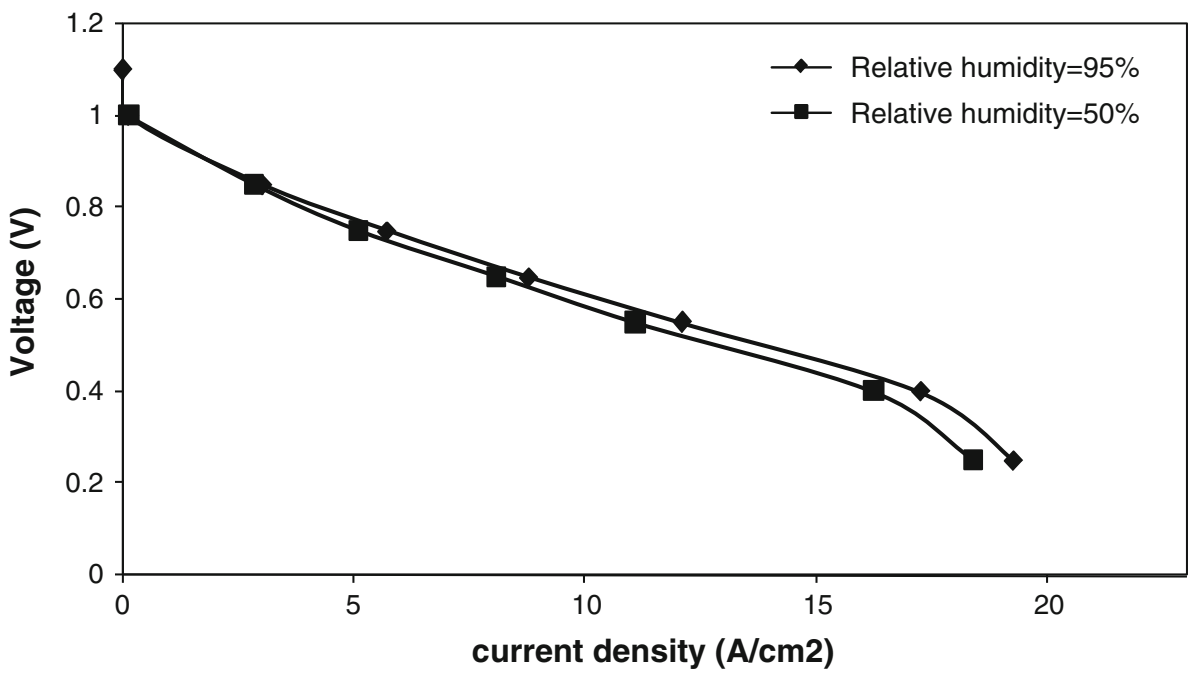


Acknowledgments This work was partially supported by Renewable Energy Organization of Iran.

\section{References}

1. Larminie, J.; Dicks, A.: Fuel Cell System Explained, 2nd edn. Wiley, New York (2003)

2. Khazaee, I.; Ghazikhani, M.: Performance improvement of proton exchange membrane fuel cell by using annular shaped geometry. J. Power Sour. 196, 2661-2668 (2011)

3. West, A.C.; Fuller, T.F.: The Influence of rib spacing in protonexchange membrane electrode assemblies. J. Appl. Electrochem. 26, 557-565 (1996)

4. Gurau, V.; Liu, H.; Kakac, S.: Two-dimensional model for proton exchange membrane fuel cells. AIChE J. 44, 2410-2422 (1998)

5. Chiang, M.S.; Chu, H.S.: Transient behavior of CO poisoning of the anode catalyst layer of a PEM fuel cell. J. Power Sour. 160, 340-352 (2006)

6. Wang, Z.H.; Wang, C.Y.; Chen, K.S.: Two-phase flow and transport in the air cathode of proton exchange membrane fuel cells. J. Power Sour. 94, 40-50 (2001)

7. Kuo, J.K.; Yen, T.S.; Chen, C.K.: Improvement of performance of gas flow channel in PEM fuel cells. Energy Convers. Manag. 49, 2776-2787 (2008)

8. Berning, T.; Djilali, N.: Three-dimensional computational analysis of transport phenomena in a PEM fuel cell-a parametric study. J. Power Sour. 124, 440-452 (2003)

9. Lobato, J.; Cañizares, P.; Rodrigo, M.A.; Piuleac, C.G.; Curteanu, S.; Linares, J.J.: Direct and inverse neural networks modelling applied to study the influence of the gas diffusion layer properties on PBI-based PEM fuel cells. Int. J. Hydrogen Energy 35, 7889-7897 (2010)
10. Lobato, J.; Cañizares, P.; Rodrigo, M.A.; Linares, J.J.; Piuleac, C.G.; Curteanu, S.: The neural networks based modeling of a polybenzimidazole-based polymer electrolyte membrane fuel cell: effect of temperature. J. Power Sour. 192, 190-194 (2009)

11. Lobato, J.; Cañizares, P.; Rodrigo, M.A.; Pinar, F.J.; Mena, E.; Úbeda, D.: Three-dimensional model of a $50 \mathrm{~cm}^{2}$ high temperature PEM fuel cell. Study of the flow channel geometry influence. Int. J. Hydrogen Energy 35, 5510-5520 (2010)

12. Khazaee, I.; Ghazikhani, M.: Performance improvement of proton exchange membrane fuel cell by using annular shaped geometry. J. Power Sour. 196, 2661-2668 (2011)

13. Lobato, J.; Cañizares, P.; Rodrigo, M.A.; Pinar, F.J.; Úbeda, D.: Study of flow channel geometry using current distribution measurement in a high temperature polymer electrolyte membrane fuel cell. J. Power Sour. 196, 4209-4217 (2011)

14. Zawodzinski, T.A.; Neeman, M.; Sillerud, L.O.; Gottesfeld, S.: Determination of water diffusion coefficients in perfluorosulfonate ionomeric membranes. J. Phys. Chem. 95, 6040-6044 (1991)

15. Zawodzinski, T.A.; Davey, J.; Valerio, J.; Gottesfeld, S.: The water content dependence of electro-osmotic drag in proton-conducting polymer electrolytes. Electrochim. Acta 40, 297-302 (1995)

16. Motupally, S.; Becker, A.J.; Weidner, J.W.: Diffusion of Water through Nafion ${ }^{\circledR} 115$ Membranes. J. Electrochem. Soc. 147, 3171$3177(2000)$

17. Miansari, ME.; Sedighi, K.; Amidpour, M.; Alizadeh, E.; Miansari, MO.: Experimental and thermodynamic approach on proton exchange membrane fuel cell performance. J. Power Sour. 190, 356-361 (2009) 